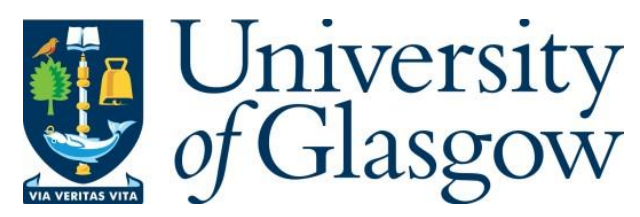

Serrano, L., Cañete, A., Garcia-Leal, T., Tomás-Gallardo, L., Flores, A., de la Torre, P., Liras, A. and Sánchez, M. (2018) Searching for a cell-based therapeutic tool for haemophilia A within the embryonic/foetal liver and the aorta-gonads-mesonephros region. Thrombosis and Haemostasis, 118(8), pp. 1370-1381.

There may be differences between this version and the published version. You are advised to consult the publisher's version if you wish to cite from it.

http://eprints.gla.ac.uk/166412/

Deposited on: 11 October 2018

Enlighten - Research publications by members of the University of Glasgow http://eprints.gla.ac.uk 
Searching for a cell-based therapeutic tool for haemophilia A within the embryonic foetal liver and the aorta-gonads-mesonephros (AGM) region.

Luis J Serrano Ramos ${ }^{1,2,}$, , Ana Cañete ${ }^{3,4,}$, , Tamara Garcia-Leal ${ }^{3}$, Laura TomásGallardo $^{3}$, Ana I Flores ${ }^{1}$, Paz de la Torre ${ }^{1}$, Antonio Liras ${ }^{1,2, * *}$ and María José Sánchez ${ }^{3, *}$.

${ }^{1}$ Grupo de Medicina Regenerativa, Instituto de Investigación Hospital 12 de Octubre, Madrid, Spain.

${ }^{2}$ Department of Physiology, School of Biology. Complutense University of Madrid. Spain.

${ }^{3}$ Centro Andaluz de Biología del Desarrollo (CABD), CSIC, UPO, JA, Seville, Spain. ${ }^{4}$ Present address, Paul O'Gorman Leukaemia Research Centre, Institute of Cancer Sciences, University of Glasgow.

\section{Corresponding author.}

María José Sánchez, PhD.

Principal Investigator CABD.

Centro Andaluz de Biología del Desarrollo (CABD),

Consejo Superior de Investigaciones Científicas (CSIC), Junta de Andalucía (JA), Universidad Pablo de Olavide (UPO),

Carretera de Utrera Km1, 41013 Seville, Spain.

Tel.: 0034 954348943; e-mail: mjsansan@upo.es

Running title: Foetal sources of coagulation FVIII, hematopoietic cells and LSECs.

The final manuscript was read and approved by all authors.

Authors declare no conflict of interest.

Work supported by the Spanish Ministry of Science and Technology Grant BFU2010-15801; Junta de Andalucia Research Funding Programme PAI-BIO-295 and the Andalusian Association of Haemophilia ASANHEMO FV2016-20. 


\section{ABSTRACT}

The development of new strategies based on cell therapy approaches to correct haemophilia A (HA) requires further insights into new cell populations capable of producing coagulation factor VIII (FVIII) and presenting stable engraftment potential. The major producers of FVIII in the adult are liver sinusoidal endothelial cells (LSEC) and in a lesser degree bone marrow (BM)-derived cells, both of which have been shown to ameliorate the bleeding phenotype in adult HA mice after transplantation. We have previously shown that cells from the foetal liver (FL) and the aorta-gonads-mesonephros (AGM) hematopoietic locations possess higher LSEC engraftment potential in new-born mice compared to adult-derived LSECs, constituting likely therapeutic targets for the treatment of HA in neonates. However less is know about the production of FVIII in embryonic locations. Q-PCR and Western blot analysis were performed to assess the relative level of FVIII production in different embryonic tissues and at various developmental stages, identifying the FL and AGM region from day 12 (E12) as prominent sources of FVIII. Furthermore, FL-derived VE-cad ${ }^{+}$CD45-Lyve1+/- endothelial/endothelial progenitor cells, presenting vascular engraftment potential, produced high levels of F8 ribonucleic acid compared to $\mathrm{CD}_{4} 5^{+}$blood progenitors or Dlk1 ${ }^{+}$ hepatoblasts. In addition, we show that the E11 AGM explant cultures expanded cells with LSEC repopulation activity, instrumental to further understand signals for in vitro generation of LSECs. Taking into account the capacity for FVIII expression, culture expansion and new-born engraftment potential, these results support the use of cells with foetal characteristics for correction of FVIII deficiency in young individuals.

Key words: foetal liver, AGM, Factor VIII, Haemophilia therapy, new-born transplantation, LSEC. 


\section{INTRODUCTION}

Haemophilia A (HA), with an incidence of one in every 5000-10,000 males worldwide $(1,2)$, is a well-known hereditary bleeding disorder. The condition is caused by different mutations in the X-linked F8 gene that encodes for the coagulation factor VIII (FVIII). F8 genetic alterations result in deficient production or dysfunction of FVIII. Current therapies involve administration of plasma derived FVIII or synthetic recombinant products. Although successful, protein replacement therapy constitutes a life-long treatment rather than a cure for the disease. Furthermore, the treatment can induce the production of neutralizing antibodies or "inhibitors" and as a consequence, patients can no longer use FVIII concentrates. Development of inhibitors can also be life threatening for high-risk patients such as infants and compromised individuals $(3,4)$. Therefore, it would be important to research into safer and viable cell-based therapies directed specially towards the treatment of the younger patients. One essential element in a cell-based therapy approach is the cell source used. Once the optimal cell type is established, iPS cell-derived protocols can potentially be tailored to obtain suitable cell types for transplantation from valid and reliable sources. Studies using cell therapy approaches (5) or cell lineage specific knockout mice $(6,7)$, have shown that secretion of endothelial-cell derived FVIII is essential for the coagulation-cascade to operate. The liver sinusoidal endothelial cells (LSEC), identified by markers such us the hyaluronan receptor-1 (Lyve1) (8), represent one of the principal producers of FVIII (9). Also hematopoietic cells from the adult can synthesize and secrete FVIII (10).

To harness novel cell subsets for HA therapeutic purposes it is crucial that transplanted cells have the capability of stably and extensively engraft endothelial and hematopoietic cells, which are the relevant producers of FVIII at therapeutic levels in experimental transplantation settings. The foetal liver (FL) and the aortagonads-mesonephros (AGM) region of the embryo contain both hematopoietic and endothelial engraftment activities (11-13). During embryonic life hematopoietic development is closely intertwined with that of the vascular system. Blood cells and endothelium emerge in close proximity at stage E7 of mouse development leading to the proposal for the existence of a common haemangioblast progenitor (14). Transplantation assays into adult irradiated 
hosts have shown that long-term multi-lineage engrafting hematopoietic stem cells (HSCs) emerge in the dorsal aorta (DA) of the AGM region at E10.5 (15). By E12, both the AGM and FL cells have hematopoietic and multi organ vascular engraftment potential, including liver sinusoidal engraftment, with FL cells contributing prominently to the vasculature $(12,13,16)$. Further characterization of E12 FL cell populations has shown that cells expressing the hemato/vascular transgenic reporter vector SCL-PLAP (17) contain both HSCs (VE-cad+/-CD45+) and cells with long-term reconstituting endothelial cell (LTR-EC) capabilities, including LSEC engraftment potential (VE-cad ${ }^{+}$CD45-Lyve1+/- cells) (13). Importantly, these VE-cad+CD45-Lyve1+/- cells present higher vascular reconstitution capacity than their adult derived LSEC counterpart cells $(13,18)$. In general FL derived cells seem to posses stronger repopulation activity compared to adult-derived progenitors, including $\operatorname{HSCs}(19,20)$ and parenchymal progenitor cells (21), thus constituting a potential target for cell therapeutic approaches.

Vascular and hematopoietic engraftment efficiency varies depending on the transplantation models and preconditioning regimes of the host. Vascular integration of transplanted adult LSECs requires extreme damage conditioning treatments of unrealistic translational values to individuals with HA, including hepatectomy, the use of highly toxic agents, irradiation or severe genetic predisposition (22-24). We have shown that FL cells can engraft blood and LSECs when transplanted into in busulfan treated new-born mice, a precondition regime that seems to be less damaging (25). Therefore transplantation of fetal cells into HA new-borns may be a suitable approach for HA treatment at early age.

While FVIII production has been well characterized in adult LSEC and blood cells $(9,10)$, very little effort has been applied to the identification of FVIII-producing locations in the developing embryo. Here we describe an extensive analysis of $F 8$ transcript production in different embryonic/foetal tissues during development, identifying a predominant window of F8 RNA expression at E12 in AGM cells and

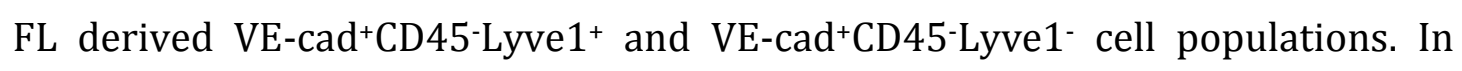
addition, it was shown that cultures of AGM explants can expand cells with LSEC engraftment potential, providing a framework to further analyse molecular mechanisms involved in the emergence/expansion of cells with LSEC potential. 
The data presented constitute the basis for further selection of novel foetal cell types with endothelial/hematopoietic engraftment potential in new-born recipient mice, which could be instrumental for early age correction of the bleeding phenotype in HA individuals.

\section{MATERIAL AND METHODS}

\section{Mice and embryo generation}

Mice were bred and housed at CABD MF and maintained in a mixed (CBA $\times$ C57BL/6) background. Wild type and SCL-PLAP transgenic mice (17) were used. To obtain embryonic/foetal tissue matings were set up and the day of vaginal plug detection was designated as embryonic day 0 . Embryos were obtained from day 8 (E8) to day 12 (E12) of gestation. Cell preparation procedures from embryonic/foetal and adult hematopoietic tissues were previously published (13, 26). All animal procedures were approved by the Universidad Pablo de Olavide Ethical Review Board and performed in compliance with Standards for Care and Use of Laboratory Animals following the European Union legislation.

\section{RNA isolation and qRT-PCR for F8}

For qRT-PCR, total RNA was extracted using NZY total RNA isolation kit (NZYtech, Ltd) and quantitated by a NanoDrop One (ThermoFisher Scientific, Massachusetts). cDNA was generated using High-Capacity cDNA Reverse Transcription Kit (Applied Biosystems, CA, USA), from $1 \mu \mathrm{g}$ of RNA as starting material. Quantitative real-time polymerase chain reaction (qRT-PCR) was performed using GoTaq® qPCR Master Mix (Promega, Wisconsin, USA), samples run on Thermal Cycler (7500 fast Real-Time PCR System, Applied Biosystems, CA, USA) on the stages: Holding stage to $50^{\circ} \mathrm{C} 2^{\prime}$ and $95^{\circ} \mathrm{C} 10^{\prime}$, Cycling Stage 40 cycles to $95^{\circ} \mathrm{C} 15^{\prime \prime}$ and $60^{\circ} \mathrm{C} 1^{\prime}$ and Melt curve Stage to 95ㅇ $15^{\prime \prime}, 60^{\circ} \mathrm{C} 1^{\prime}, 95^{\circ} \mathrm{C} 30^{\prime \prime}$ and

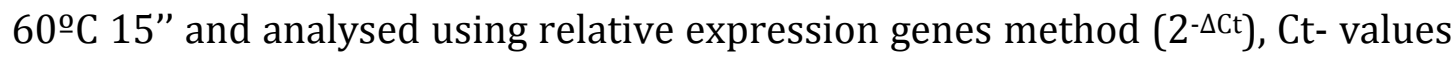
were processed and normalized to GAPDH to account for total amount of RNA in each individual sample. Samples contained tissues from at least two different embryos and were run in triplicates. Each biological replica was obtained from individual pregnant females. The PCR primers designed for mouse $F 8$ and GAPDH genes are shown in Table 1. 


\section{Western Blot}

FVIII production was analysed by Western blotting. In brief, samples obtained from E12 embryo tissues, adult liver and 1x106 HepG2 cell line were frozen, resuspended in SDS buffer (100 mM TrisHCl pH 6.8, 4\% SDS, 20\% glycerol) with protease inhibitor cocktail (Roche Applied Bioscience) and lysed by sonication at $10 \%$ amplitude with 10 pulses of $10 \mathrm{sec}$ on/10 sec off. After sonication, samples were centrifuged at $16.000 \mathrm{~g}$ for $20 \mathrm{~min}$ at $4^{\circ} \mathrm{C}$ and supernatants were collected. Protein concentrations were measured using the RC/DC Protein Assay kit (BioRad). Total protein extract from embryonic tissues, HepG2 cell lysate and adult liver were loaded in 7.5\% TGX Stain-Free ${ }^{\mathrm{TM}}$ FastCast $^{\mathrm{TM}}$ Acrylamide (BioRad) gel under reducing conditions and blotted onto Nitrocellulose membranes. The Precision Plus Protein Standard All Blue (BioRad) was run in the same gel. Western Blot normalization was performed using total protein load following manufacturer protocol for Stain Free gels kit (Bio Rad). FVIII monoclonal antibody (R8B12) (sc-73597) that recognises the A2 domain of the human and mouse FVIII heavy chain, used at 1:250 dilution and the (RFFVIII C/5) (sc-59512) that recognises de FVIII light chain, used at 1:400 were employed as primary antibodies, followed by incubation with m-IgGk BP-HRP secondary antibody (Santa Cruz Biotechnology, sc-516102) diluted to 1:2000. Chemiluminiscent signals were detected with ECL Prime reagent (GE Healthcare) in a ChemiDoc XRS Imaging System (BioRad). Cell lysates from human HepG2 hepatocellular carcinoma cell line were kindly provided by Dr JA Sanchez Alcazar, CABD, Seville.

\section{Cell analysis and sorting by flow cytometry}

Cell suspensions were stained, analysed and separated by flow cytometry as previously described (13). A FACSAria flow cytometer equipped with two lasers and run with a FACSDiva software (BD Biosciences, www.bdbiosciences.com/eu) was used.

\section{AGM and FL explant cultures}

AGM and FL were dissected form E11 embryos and cultured in explants for 3 days as previously described $(11,15,27)$. Briefly, AGMs and FL were removed in D-PBS 
$\mathrm{Ca}+\mathrm{Mg}_{+}$(Sigma-Aldrich, USA), deposited on $0.65 \mu \mathrm{m}$ nylon filters (DVPP02500 Millipore, USA) placed on metallic supports immersed in 6 well plates containing $5 \mathrm{ml}$ myeloid long-term culture medium (M5300 Stem Cell Technologies, Canada) supplemented with $10 \mu \mathrm{M}$ hydrocortisone (H2270 Sigma, Germany) in an airliquid interphase. For cell suspension, FL and FLex were mechanically homogenate. Uncultured AGM and AGM explanted tissues were incubated in 0.12\% collagenase type XI (Sigma-Aldrich, USA) in D-PBS (Sigma-Aldrich, USA) supplemented with 5\% FCS (GE Helthcare, HyClone, USA) and 100U/ml penicillin, $100 \mu \mathrm{g} / \mathrm{ml}$ streptomycin $\left(1 \% \mathrm{P} / \mathrm{S}\right.$ ) (GE Helthcare, HyClone, USA) at $37^{\circ} \stackrel{\mathrm{C}}{ }$ for 30 min, further dissociated by pipetting and centrifuged in D-PBS 10\% FSC. For transplantation cells were re-suspended in D-PBS 1\%FCS 1\%P/S.

\section{Transplantation into busulfan treated new-born mice and hematopoietic and vascular chimerism determination}

Uncultured and explanted AGM and FL cell suspension obtained from SCL-PLAP transgenic embryos, were injected intravenously (i.v.) into busulfan conditioned 2 days old wild type new-born mice following previously published protocols (13, 28). For details of AGM and FL embryo equivalents/cell numbers injected and the number of experiments performed see Table 2. After 4 months mice were anesthetized, blood collected from the heart and perfused with $50 \mathrm{ml}$ Trisbuffered saline containing $0.001 \%$ heparin. For determination of hematopoietic chimerism, blood samples were depleted of erythroid cells (12), stained for CD45 and PLAP and analysed by flow cytometry for quantification of the donor-derived reporter gene PLAP. The SCL-PLAP reporter vector is only expressed in a proportion of circulating cells in transgenic mice detected by FACS analysis $(15 \pm 5 \%)$. A correlation between the level of chimerism in peripheral blood determined by FACS-PLAP and semi-quantitative PCR-PLAP for genomic DNA was previously established, showing that values $\geq 5 \%$ by FACS-PLAP correspond to 10 $100 \%$ total hematopoietic chimerism determined by semi-quantitative PCR-PLAP $(12,13)$. Host animals presenting $>1 \%$ of PLAP $^{+}$cells by flow cytometry in circulation were considered as hematopoietic chimeras (equivalent to approximately $5 \%$ of total donor chimerism). PCR-PLAP on genomic DNA was used to determine the presence of donor-derived cells in mice from which blood 
samples were not available for FACS analysis (see Table 2). For vascular engraftment valuation, the liver was removed, fixed in zinc solution (BDPharmingen CA, USA) and wax embedded. Nitroblue tetrazolium (NBT) staining on host liver sections was performed to detect the donor-derived human alkaline phosphatase (SCL-PLAP) transgene expression. Systematic histological screening for SCL-PLAP+ donor-derived sinusoidal vascular-like clusters (v.c.) on liver sections was performed as previously published $(12,13)$. For quantification of vascular engraftment on NBT stained liver sections the frequency of mice positive for v.c. and the relative tissue area containing v.c., denominated vascular cluster area (v.c.a.), were determined using the Image AnalySIS software program V3.1.110 as published (13).

\section{Histological staining}

Triple immune-staining for reporter gene hPLAP, pan-leukocyte marker CD45 and endothelial marker Isolectin B4 (IsoB4) was performed on paraffin liver sections to confirm the endothelial nature of the v.c. as described (12). DAPI staining was used to identify the nuclei. Images were taken with a Leica SP2 confocal microscope.

\section{Statistical analysis}

Data are expressed as mean \pm SD. Relation of $F 8$ RNA level production and age within whole embryos and tissues was assessed by means of regression analysis taking the logarithm of the $2^{-\Delta \mathrm{Ct}}$ values as dependent variable and the stage as independent variable. To evaluate if there were differences in the expression of F8 RNA at stage E12 between the different tissues a U-MannWhitney test was carried out. The Statgraphics Centurion XVII software (Statpoint Technologies, Inc. USA) was used.

\section{RESULTS}

\section{FVIII expression during mouse embryo development}

Total RNA was obtained from whole embryos and the relative levels of $F 8$ transcripts determined by qPCR using GAPDH as normalization control. This analysis showed consistent increment on the F8 RNA expression levels from E8 to 
E12 stages (Figure 1A, Sup Table 1). To assess the spatio-temporal expression of F8 in specific embryonic/foetal locations, hematopoietic sites previously described to contain endothelial progenitors/endothelial cells were analysed, including the FL, AGM region and yolk sac (YS) $(13,14)$. From E10 to E12 very little variation in F8 RNA production levels occurred in the YS or FL compared with the progressive increase observed in the AGM region, with values in E12 AGM approximately 8 times higher than liver and yolk sac (Figure 1B). As FVIII production has been detected in different types of endothelium from the adult individuals (9), the level of F8 RNA expression was also analysed from embryonic regions with less prominent or negative hematopoietic activity including the heart, head, dorsal-intermedial somites and limbs. In all tissues analysed it was observed a progressive increase of F8 RNA expression from E9 to E12 embryonic stages, superior to the production of $F 8$ by the FL (Figure 1B). Statistical regression analysis indicated a significant $(\mathrm{p}<0.05)$ correlation of age and increment on F8 RNA production in most samples, except for the yolk sac (YS) (Sup. Table 1). This might be associated with an increment of vasculogenesis associated to organogenesis, emphasized from E10-E11 $(29,30)$. Still the E12 AGM region presented significant higher levels for F8 transcripts than any other tissue analysed.

To assess FVIII protein production, we performed Western blot analysis with E12derived tissue lysates using adult liver andHepG2 cells line as positive controls. FVIII is synthesized as an approximately $300 \mathrm{kDa}$ full-length protein consisting of A1-A2-B-A3-C1-C2 structural domains. The native protein is processed intracellularly into a heterodimer comprising a heavy chain (HC), including the A1-A2$\mathrm{B}$ domains, with a molecular weight ranging from 90 to $200 \mathrm{kDa}$ depending on the length of the B domain, and a light chain (LC) of $80 \mathrm{kDa}$ (A3-C1-C2 domains) (3133) . Using an anti-FVIII monoclonal antibody that recognizes an epitope in the A2 domain, we detected different bands with a size corresponding to the unprocessed full-length protein, different processed HC fragments and an approximately 37 $\mathrm{kDa}$ band, likely corresponding to the A2 domain (34) (Figure 1D). The approximately $300 \mathrm{kDa}$ band was detected in most foetal tissue samples, except for the YS (Figure 1D, i). Although we detected different processed fragments,we could not detect the full-length protein in the HepG2 or adult liver positive 
controls, even after incrementing the amount of protein loading for adult liver (Figure 1D, ii). This may suggest a difference in FVIII processing between adult liver, the tumour cell line and cells of foetal origin. HC bands were present in most tissue samples, including the approximately $200 \mathrm{kDa}$ peptide, likely corresponding to the A1-A2-B fragment, and a double band at approximately 100 $\mathrm{kDa}$ comprising the 90-kDa fragment (A1-A2). The 90-kDa band was faint in foetal tissues and prominent in the adult liver (Figure 1D). The only exception was the YS where HC proteins were absent, in accordance with the low levels for F8 RNA expression. We also detected a low molecular weight band of approximately 37 $\mathrm{kDa}$ in foetal tissues that was absent in the adult liver (Figure 1D). The 37- kDa band is present in the positive control HepG2 human cell line, reported to produce low levels of functional FVIII, $(35,36)$, supporting the idea that this fragment likely correspond to the A2 domain (Figure 1D). Classically, the A2 product is generated during thrombin-catalysed cleavage or proteolytic degradation, (31) hence we can only speculate that the detection in our samples might be due to its accumulation as a product of fast cytoplasmic processing of non-secreted FVIII, particularly accentuatedinHepG2,where almost noother bandisdetected. Most FVIIImight besecretedin the adult liver andconsequently no A2 product is detected. Mechanisms controlling intracellular FVIII proteolytic cleavage and fragment dissociation have been described in transfected cell lines, although it is not completely clear if similar mechanism apply to tissue-derived cells. $(37,38)$ To discard background cross-reactivity bands, we also performed membrane stained with only the secondary antibody. The only product detectedwas the approximately $60 \mathrm{kDa}$ band (not shown), indicating that the A2 fragment is not unspecific. Overall, the presence of properly cleaved HC fragments suggests that the correct synthesis and processing of FVIII is occurring in E12 tissues.

To further corroborate the processing of FVIII protein in foetal tissues, we also tested an anti-FVIII monoclonal antibody that recognizes the LC. Although the fulllength protein was only detected in the foetal head and somites, all samples presented the approximately $80-\mathrm{kDa}$ band corresponding to the LC fragment, except for the YS and HepG2 (Supplementary Fig. S2, available in the online version). We cannot discard that the absence of the full-length band in some samples might be due to the lack of reactivity of the LC antibody related to the 
characteristic of the tissues. More work will be needed to determine the precise cell types and the operating mechanisms for the synthesis, storage and secretion of FVIII and its correlation with the presence of different fragment sizes and band intensity in Western blot analysis.

\section{F8 RNA production in different cell populations from E12 FL}

The liver has been considered for a long time as the primary site of FVIII production since canine or human liver transplantation corrected HA $(39,40)$. Further work showed that liver LSEC are the main cellular source of hepatic FVIII $(6,7,9)$. Cell-types other than endothelial cells with the capacity to synthesize and release FVIII have been identified in hepatic and extra hepatic locations in the adult, including hepatocytes, monocytes, macrophages, megakaryocytes and mesenchymal stromal cells (10). We have characterized a Ve-cad ${ }^{+}$CD 45 -Lyve1+/cell population from the E12 FL with multi-organ vascular engraftment potential and a prominent contribution to the liver endothelial sinusoids (13). This cell population contained in vitro hemato/endothelial (VE-cad+CD45-Lyve1-) and endothelial (VE-cad ${ }^{+}$CD45-Lyve1+) activity and was different from the VE-cad ${ }^{+/}$ $\mathrm{CD} 45^{+}$cell subset that contained both HSC and hematopoietic progenitors (HP). To determine the relative levels of $F 8$ RNA production in the different E12 FL cell subsets, FACS sorting for hemato/endothelial cells (VE-cad ${ }^{+}$CD45-Lyve1-), endothelial sinusoidal progenitor cells (VE-cad +CD45-Lyve1+), leukocytes (VE$\mathrm{cad}^{\left.+/-C D 45^{+}\right)}$and non-endothelial, non-leukocyte cells (VE-cad-CD45-) was performed (Figure 2A). Also F8 RNA production by foetal hepatocytes and enriched fraction of mesenchymal cells was assessed. Cells were FACS sorted based on expression of the Dlk1 hepatoblast marker (41) and exclusion of endothelial, blood and erythroid cells (VE-cad-CD45-Ter119-Dlk1+ as hepatoblasts and VE-cad-CD45-Ter119-Dlk1- as a cell subset that included mesenchymal cells $(42,43)$ (Figure 2B). Higher levels for $F 8$ RNA expression were observed in VE-cad ${ }^{+} \mathrm{CD} 45$-Lyve1- hemato/endothelial progenitors and VEcad $^{+}$CD45-Lyve1 ${ }^{+}$endothelial sinusoidal progenitor cells compared with $\mathrm{CD} 45^{+}$ blood cells, Dlk1+ hepatoblasts or other cell types included in the VE-cad-CD45Ter119-Dlk1- cell population (Figure 2C). This result indicates that, similarly to 
the adult liver (10), the main population producing F8 RNA in the FL is of endothelial nature.

It is of note the relative low level of F8 RNA production of unfractionated E12 FL cells compared to adult liver. This is consistent with the fact that in the adult liver the main cellular components, endothelial cells and hepatocytes, were reported to produce F8 RNA $(10,44)$ while Ve-cad ${ }^{+} \mathrm{CD} 45-\mathrm{Lyve}^{+/-}$cells only represent the $0.6 \pm 0.2 \%$ of E12 FL cells, an organ mostly composed by erythroblast at this stage. Further studies are required to determine if endothelial progenitors/endothelial cells are also the main producers of F8 RNA in the different embryonic locations.

\section{The AGM explant culture expands cells with LSEC engraftment potential}

Establishment of culture systems for differentiation/proliferation of foetal progenitor cells with LSEC vascular potential is of interest for therapeutic applications. As both hematopoietic and endothelial progenitor cell subsets can be involved in the efficient vascular engraftment $(45,46)$ and FVIII production $(10)$, we reasoned that the AGM explant (AGMex) culture system, supportive of both hematopoietic and some types of endothelial/endothelial precursor expansion (47-49) could be optimal. To test this idea, AGMex from E11 SCL-PLAP transgenic embryos were set up for 3 days, followed by cell suspension and transplantation of $30 \times 10^{4}$ cells i.v. into busulfan treated newborn recipient mice. Cells from uncultured E11 AGMs were also transplanted as control. At 4 months posttransplantation hematopoietic and liver vascular engraftment were assessed (scheme in Figure 3A). Hematopoietic engraftment was observed in all mice transplanted with cells from AGMex ( 8 out of 8 ) as determined by FACS for the PLAP reporter gene expression in peripheral blood (Figure 3 B, Table 2). This constituted a robust increment in hematopoietic engraftment frequency compared to controls transplanted with uncultured E11 AGM cells (8 out of 17) in agreement with previous reports (Table 2, Figure 3A) (15). Immuno-histological analysis of liver sections from chimeras showed that only animals transplanted with cells from AGMex presented $\mathrm{PLAP}^{+}$donor endothelial cell engraftment in the liver (3 out of 8) resembling LSEC cells (Figure 3C), similar to the frequency of vascular chimerism obtained from E12 AGM cells (4 out of 10, not shown) (13), while control mice transplanted with uncultured E11 AGM cells did not present 
donor derived vascular clusters in the liver (0 out of 8). Phenotypic analysis of cells from AGMex did not show an increment on VE-cad+CD45-Lyve1+/- cells (Figure 3D). Indeed, the frequency of VE-cad and Lyve-1 dropped drastically compared to CD45 cells after the explants. Considering that culture medium components are not defined, we cannot exclude the possibility that down regulation/internalization of the VE-cad and Lyve-1 receptors might occur during AGM culture as described for dermal tissue explants under the influence of proinflamatory signals (50). More work is needed to determine the characteristics of cells with LSEC engraftment potential and their relation to FL derived cells. Altogether this indicates that E11 AGM explant cultures promoted LSEC engraftment activity.

FLex cultures have been shown unsuitable for expansion of HSC potential (15), but this did not exclude the possibility that they could maintain/expand LSEC activity. Thus FLs were cultured in similar conditions as AGMex. Cells from FLex were transplanted and mice were analysed at 4 months. A drastic reduction in hematopoietic engraftment activity was observed from FLex cells (1 out of 9) compared to cells from uncultured FL (5 out of 6), in agreement with results from other groups (15) (Figure 3A, Table 2). Also, no increment in vascular engraftment was obtained from FLex compared with uncultured controls as only one of the 8 mice analysed presented PLAP+ donor derived LSECs while all FL transplanted mice presented vascular grafts (Figure 3C, Table 1). This indicates that FLex are not optimal to promote vascular or hematopoietic engraftment activity.

\section{DISCUSSION}

Different types of primary postnatal cells capable of producing FVIII have been used in transplantation for correction of bleeding phenotype of adult HA mice, including adult LSEC (5) and blood cells $(10,51)$, however adult LSEC can not engraft the liver when transplanted into busulfan conditioned new-born recipient mice (13). In the same way, adult BM-derived HSCs are less efficient than FL cells to repopulate the adult (19) or new-born hematopoietic system (52). FL and AGM derived cells efficiently engraft both the hematopoietic system and LSECs when 
transplanted in new-born individuals (13), providing simultaneously with blood and endothelial daughter cell types that can potentially produce FVIII upon engraftment. Moreover, the concurrent administration of hematopoietic and endothelial progenitors can be beneficial for vascular integration as it has been shown that hematopoietic-derived cells produce paracrine factors that promote neo-angiogenesis upon vascular injury in diverse tissues $(45,46)$, including promotion of LSECs proliferation in the damaged liver (53). Therefore, it is of interest to characterize foetal cells as potential targets for HA cell therapy in neonatal and young individuals, a stage when adult derived cells seem to engraft less robustly, if at all. The work presented here demonstrates the expression of FVIII in FL and AGM cells and shows that AGMex can expand cells with LSEC engraftment potential, providing the bases to further assess their ability to long term rescue FVIII production and bleeding coagulation deficiencies in new-born and adult HA mice.

In the experiments presented here a degree of correlation between levels of FLderived hematopoietic and vascular engraftment were not observed. This does not exclude the possibility that donor-derived pro-angiogenic activity could rely in a subset of hematopoietic cells not directly derived from HSCs or their descendent cells. Indeed, fetal myeloid cells have been reported to contribute to vessel anastomosis and remodeling during embryogenesis $(54,55)$. Moreover, previous results from our group showed that transplantation of E12 FL VeCad+CD45-Lyve+/- cells, devoid of HSC activity, resulted in long term vascular engraftment of recipient mice. Interestingly, Ve-Cad+CD45- Lyve+/- chimeras, presented vascular clusters that also included few donor derived CD $45^{+}$cells (13). These results indicated that hematopoietic cells associated with the vascular grafts, potentially pro-angiogenic, were not derived from HSCs or their descendants. Thus, a correlation of hematopoietic and vascular repopulation might not always occur. Incrementing the number of chimeras and performing cotransplantation assays with different FL HSC/myeloid/macrophage cell subsets $(54,55)$ would be necessary to determine the contribution of different fetal CD45+ hematopoieitc cells for vascular graft formation.

In agreement with previous results a basal level of FVIII production has been evidenced during mouse embryonic development (56). The progressive age raise 
on F8 transcripts in the whole embryo correlated with an increase of F8 in different locations, potentially related to a general increase of angiogenesis during mid gestation $(29,30)$. The first mesodermic angioblast progenitors appear around day 7 (E7) of mouse development. By E8 angioblasts aggregate forming a simple circulatory circuit consisting of a heart, dorsal aorta, yolk sac plexus and sinus venosus. This circuit is remodelled by extensive endothelial cell proliferation and maturation, generating a complex vascular network of endothelial tubes including arteries, veins and lymphoid vessels that specialize in each organ (29). Considering that, in the adult mice the principal EC types producing FVIII are LSEC and lymphoid endothelium (9), it is expected that the concomitant increment on embryonic $\operatorname{LSECs}(57,58)$ and lymphoid vessels by stage E12 (59) should have an impact on FVIII expression levels. It is of interest that the E12 AGM constitutes one of the main producers of FVIII, significantly higher than FL at the RNA and protein level. We speculate that the FVIII could be produced by the dorsal aorta (DA) VE-cad ${ }^{+} \mathrm{CD} 45^{-}$endothelial cells (EC), a heterogeneous population constituted by structural EC, including Lyve1+ cells (13, 60), and hemogenic endothelial cells (HEC) capable of generating HSC and hematopoietic progenitor cells (14). Characterization of distinctive markers and transcriptomic profiling for EC, HEC and HC has been a topic of intense interest, however the expression of FVIII has not been reported as far as we know. This could be because most studies related to HEC and HSC have focused on early embryonic stages (E10-E11) that produce much reduced levels of F8 RNA as shown here (Figure 1) $(61,62)$. It remains to be determined what types of AGMderived ECs produce FVIII, the relation with Lyve1+ cells and the LSEC engraftment ability.

Data showing the FVIII protein secretion by human FL derived LSECs would support this functionality in counterpart VE-cad+CD45-Lyv1+/- mouse cells (24). Fomin et al have characterized the LSECs in human FL as CD $14^{++}$CD $45^{-}$cells expressing the EC markers VE-cad and CD31, molecules expressed by the murine cells (13). CD14++CD45- cells form part of the liver sinusoids and constitute the main human FL population producing F8 RNA, similar to murine VE-cad+CD45Lyv1+/- cells. Transplanted unfractionated human FL cells into adult uPA-NOG mice, immuno-deficient mice overexpressing an urokynase-type plasminogen 
activator under albumin promoter, engrafted the hematopoietic system and LSEC. Importantly, engrafted mice presented levels of human derived FVIII in circulation similar to those found in human plasma (24). This information in combination with our Western blot results, supports the idea that FL derived cells can produce FVIII protein. Still, transplantation of FL cell subsets into HA mice remains to be done to determine specific/synergistic FVIII secretion by hematopoietic and LSEC engrafted cells and long-term amelioration of the bleeding phenotype.

Culture conditions that promote long-term maintenance of LSECs for transplantation remain challenging as LSEC lose their characteristics in vitro (63). The results shown here indicate that AGMex culture constitutes an alternative to expand cells with LSECs engraftment potential. AGMex and derivatives were described more than two decades ago as a culture system capable of expanding different mesoderm progenitor cells, including HSCs and hematopoietic progenitor cells (15) and aorta-derived myogenic cells and mesoangioblast progenitor (47). AGM cell suspension cultures have also shown expansion of high proliferative potential hemangioblast (HPP-HA) precursors, endothelial progenitors and endothelial cells $(49,64)$. Here we have shown for the first time that AGMex can also expand cells with LSEC engraftment potential. For therapeutic purposes, the AGMex culture could be used in combination with FVIII gene transfer strategies, generally effective in 2-3 days, and provide a working frame to characterize molecules instrumental in the more effective derivation of LSEC from iPSCs (65). Advanced cell therapy approaches could promote a curative treatment of severe HA at early age, an inherited disease that presently, can only be palliatively treated.

\section{AUTHOR CONTRIBUTIONS.}

*Luis J Serrano Ramos: collection and/or assembly of data, data analysis and interpretation. *Ana Cañete: collection and/or assembly of data, data analysis and interpretation. Tamara Garcia-Leal: collection and/or assembly of data. Laura Tomas-Gallardo: collection and/or assembly of data. Ana I Flores: revised critically the manuscript for important intellectual content. Paz de la Torre: revised critically the manuscript for important intellectual content. **Antonio 
Liras: Conception and design, financial support, revised critically the manuscript. **Maria José Sanchez: Conception and design, data analysis and interpretation, collection and assembly of data, financial support, manuscript writing. *These authors have contributed equally as first authors. ${ }^{* *}$ These authors have contributed equally as principal researchers to this work.

\section{ACKNOWLEDGMENTS}

The authors thank A.M. Castro for assistance with preparation of sections; K. GarciaGarcia and Corin Ramos for assistance with flow cytometry and confocal microscopy; Candi Mateos, Ana Franco and Alberto Ramos for their support with the animal husbandry; Abel Sánchez Jímenez, Department of Biomathematics, Complutense University, Madrid, for advise on statistical analysis and James Castelli-Gair Hombria and Jaime Carvjal for critical reading and editing of the manuscript. This work was supported by the Spanish Ministry of Education and Science Grant BFU2010-15801 and Junta de Andalucia Grants PAI-BIO-295 to MJS and XXX grant to AL, AF and PT. Also this study was supported by the Andalusian Association of Hemophilia (ASANHEMO). The funders had no role in study design, data collection and analysis, decision to publish, or preparation of the manuscript.

\section{REFERENCES}

1. Fomin ME, Togarrati PP, Muench MO. Progress and challenges in the development of a cell-based therapy for hemophilia A. Journal of thrombosis and haemostasis : JTH 2014; 12(12): 1954-65.

2. Stonebraker JS, Brooker M, Amand RE, et al. A study of reported factor VIII use around the world. Haemophilia : the official journal of the World Federation of Hemophilia 2010; 16(1): 33-46.

3. Witmer C, Young G. Factor VIII inhibitors in hemophilia A: rationale and latest evidence. Therapeutic advances in hematology 2013; 4(1): 59-72.

4. Hay CR, Palmer B, Chalmers E, et al. Incidence of factor VIII inhibitors throughout life in severe hemophilia A in the United Kingdom. Blood 2011; 117(23): 6367-70.

5. Follenzi A, Benten D, Novikoff $P$, et al. Transplanted endothelial cells repopulate the liver endothelium and correct the phenotype of hemophilia A mice. The Journal of clinical investigation 2008; 118(3): 935-45. 
6. Fahs SA, Hille MT, Shi Q, et al. A conditional knockout mouse model reveals endothelial cells as the principal and possibly exclusive source of plasma factor VIII. Blood 2014; 123(24): 3706-13.

7. Everett LA, Cleuren AC, Khoriaty RN, et al. Murine coagulation factor VIII is synthesized in endothelial cells. Blood 2014; 123(24): 3697-705.

8. Mouta Carreira C, Nasser SM, di Tomaso E, et al. LYVE-1 is not restricted to the lymph vessels: expression in normal liver blood sinusoids and downregulation in human liver cancer and cirrhosis. Cancer research 2001; 61(22): 8079-84.

9. Pan J, Dinh TT, Rajaraman A, et al. Patterns of expression of factor VIII and von Willebrand factor by endothelial cell subsets in vivo. Blood 2016; 128(1): 1049.

10. Zanolini D, Merlin S, Feola M, et al. Extrahepatic sources of factor VIII potentially contribute to the coagulation cascade correcting the bleeding phenotype of mice with hemophilia A. Haematologica 2015; 100(7): 881-92.

11. Sanchez MJ, Holmes A, Miles C, et al. Characterization of the first definitive hematopoietic stem cells in the AGM and liver of the mouse embryo. Immunity 1996; 5(6): 513-25.

12. Garcia-Ortega AM, Canete A, Quinter C, et al. Enhanced hematovascular contribution of SCL 3' enhancer expressing fetal liver cells uncovers their potential to integrate in extramedullary adult niches. Stem cells 2010; 28(1): 100-12.

13. Canete A, Comaills V, Prados I, et al. Characterization of a Fetal Liver Cell Population Endowed with Long-Term Multiorgan Endothelial Reconstitution Potential. Stem cells 2017; 35(2): 507-21.

14. Lacaud G, Kouskoff V. Hemangioblast, hemogenic endothelium, and primitive versus definitive hematopoiesis. Experimental hematology 2017; 49: 19-24.

15. Medvinsky A, Dzierzak E. Definitive hematopoiesis is autonomously initiated by the AGM region. Cell 1996; 86(6): 897-906.

16. Taoudi S, Morrison AM, Inoue $\mathrm{H}$, et al. Progressive divergence of definitive haematopoietic stem cells from the endothelial compartment does not depend on contact with the foetal liver. Development 2005; 132(18): 4179-91.

17. Silberstein L, Sanchez MJ, Socolovsky M, et al. Transgenic analysis of the stem cell leukemia +19 stem cell enhancer in adult and embryonic hematopoietic and endothelial cells. Stem cells 2005; 23(9): 1378-88.

18. Filali EE, Hiralall JK, van Veen HA, et al. Human liver endothelial cells, but not macrovascular or microvascular endothelial cells, engraft in the mouse liver. Cell transplantation 2013; 22(10): 1801-11.

19. Szilvassy SJ, Meyerrose TE, Ragland PL, et al. Differential homing and engraftment properties of hematopoietic progenitor cells from murine bone marrow, mobilized peripheral blood, and fetal liver. Blood 2001; 98(7): 2108-15. 20. Bowie MB, Kent DG, Dykstra B, et al. Identification of a new intrinsically timed developmental checkpoint that reprograms key hematopoietic stem cell properties. Proceedings of the National Academy of Sciences of the United States of America 2007; 104(14): 5878-82.

21. Dabeva MD, Petkov PM, Sandhu J, et al. Proliferation and differentiation of fetal liver epithelial progenitor cells after transplantation into adult rat liver. The American journal of pathology 2000; 156(6): 2017-31. 
22. Benten D, Follenzi A, Bhargava KK, et al. Hepatic targeting of transplanted liver sinusoidal endothelial cells in intact mice. Hepatology 2005; 42(1): 140-8.

23. Krause $P$, Rave-Frank M, Wolff HA, et al. Liver sinusoidal endothelial and biliary cell repopulation following irradiation and partial hepatectomy. World journal of gastroenterology 2010; 16(31): 3928-35.

24. Fomin ME, Zhou Y, Beyer AI, et al. Production of factor VIII by human liver sinusoidal endothelial cells transplanted in immunodeficient uPA mice. PloS one 2013; 8(10): e77255.

25. Zeng L, Jia L, Xu S, et al. Vascular endothelium changes after conditioning in hematopoietic stem cell transplantation: role of cyclophosphamide and busulfan. Transplantation proceedings 2010; 42(7): 2720-4.

26. Sanchez M, Gottgens B, Sinclair AM, et al. An SCL 3' enhancer targets developing endothelium together with embryonic and adult haematopoietic progenitors. Development 1999; 126(17): 3891-904.

27. Crisan M, Kartalaei PS, Vink CS, et al. BMP signalling differentially regulates distinct haematopoietic stem cell types. Nature communications 2015; 6: 8040.

28. Yoder MC, Hiatt K. Engraftment of embryonic hematopoietic cells in conditioned newborn recipients. Blood 1997; 89(6): 2176-83.

29. Walls JR, Coultas L, Rossant J, et al. Three-dimensional analysis of vascular development in the mouse embryo. PloS one 2008; 3(8): e2853.

30. Aird WC. Phenotypic heterogeneity of the endothelium: II. Representative vascular beds. Circulation research 2007; 100(2): 174-90.

31. Fay PJ, Smudzin TM, Walker FJ. Activated protein C-catalyzed inactivation of human factor VIII and factor VIIIa. Identification of cleavage sites and correlation of proteolysis with cofactor activity. The Journal of biological chemistry 1991; 266(30): 20139-45.

32. Rosenberg JB, Foster PA, Kaufman RJ, et al. Intracellular trafficking of factor VIII to von Willebrand factor storage granules. The Journal of clinical investigation 1998; 101(3): 613-24.

33. Liu L, Mah C, Fletcher BS. Sustained FVIII expression and phenotypic correction of hemophilia A in neonatal mice using an endothelial-targeted sleeping beauty transposon. Molecular therapy : the journal of the American Society of Gene Therapy 2006; 13(5): 1006-15.

34. Pittman DD, Millenson $\mathrm{M}$, Marquette $\mathrm{K}$, et al. A2 domain of human recombinant-derived factor VIII is required for procoagulant activity but not for thrombin cleavage. Blood 1992; 79(2): 389-97.

35. Roth SD, Schuttrumpf J, Milanov P, et al. Chemical chaperones improve protein secretion and rescue mutant factor VIII in mice with hemophilia A. PloS one 2012; 7(9): e44505.

36. Brown HC, Wright JF, Zhou S, et al. Bioengineered coagulation factor VIII enables long-term correction of murine hemophilia A following liver-directed adeno-associated viral vector delivery. Molecular therapy Methods \& clinical development 2014; 1: 14036.

37 Wei W, Zheng C, Zhu M, et al. Missense mutations near the Nglycosylation site of the A2 domain lead to various intracellular trafficking defects in coagulation factor VIII. Sci Rep 2017; 7:45033

38 Orlova NA, Kovnir SV, Vorobiev II, Gabibov AG, Vorobiev AI. Blood clotting factor VIII: fromevolution to therapy. Acta Naturae 2013; 5(02):19-39 
39. Storb R, Kolb HJ, Graham TC, et al. The effect of prior blood transfusions on hemopoietic grafts from histoincompatible canine littermates. Transplantation 1972; 14(2): 248-52.

40. Bontempo FA, Lewis JH, Gorenc TJ, et al. Liver transplantation in hemophilia A. Blood 1987; 69(6): 1721-4.

41. Nierhoff D, Ogawa A, Oertel M, et al. Purification and characterization of mouse fetal liver epithelial cells with high in vivo repopulation capacity. Hepatology 2005; 42(1): 130-9.

42. Mendes SC, Robin C, Dzierzak E. Mesenchymal progenitor cells localize within hematopoietic sites throughout ontogeny. Development 2005; 132(5): 1127-36.

43. Ito K, Yanagida A, Okada $\mathrm{K}$, et al. Mesenchymal progenitor cells in mouse foetal liver regulate differentiation and proliferation of hepatoblasts. Liver international : official journal of the International Association for the Study of the Liver 2014; 34(9): 1378-90.

44. Do H, Healey JF, Waller EK, et al. Expression of factor VIII by murine liver sinusoidal endothelial cells. The Journal of biological chemistry 1999; 274(28): 19587-92.

45. Okuno Y, Nakamura-Ishizu A, Kishi K, et al. Bone marrow-derived cells serve as proangiogenic macrophages but not endothelial cells in wound healing. Blood 2011; 117(19): 5264-72.

46. Kim H, Cho HJ, Kim SW, et al. CD31+ cells represent highly angiogenic and vasculogenic cells in bone marrow: novel role of nonendothelial CD31+ cells in neovascularization and their therapeutic effects on ischemic vascular disease. Circulation research 2010; 107(5): 602-14.

47. Minasi MG, Riminucci M, De Angelis L, et al. The meso-angioblast: a multipotent, self-renewing cell that originates from the dorsal aorta and differentiates into most mesodermal tissues. Development 2002; 129(11): 277383.

48. de Bruijn MF, Ma X, Robin C, et al. Hematopoietic stem cells localize to the endothelial cell layer in the midgestation mouse aorta. Immunity 2002; 16(5): 673-83.

49. Nishikawa M, Tahara T, Hinohara A, et al. Role of the microenvironment of the embryonic aorta-gonad-mesonephros region in hematopoiesis. Annals of the New York Academy of Sciences 2001; 938: 109-16.

50. Johnson LA, Prevo R, Clasper S, et al. Inflammation-induced uptake and degradation of the lymphatic endothelial hyaluronan receptor LYVE-1. The Journal of biological chemistry 2007; 282(46): 33671-80.

51. Follenzi A, Raut S, Merlin S, et al. Role of bone marrow transplantation for correcting hemophilia A in mice. Blood 2012; 119(23): 5532-42.

52. Arora N, Wenzel PL, McKinney-Freeman SL, et al. Effect of developmental stage of HSC and recipient on transplant outcomes. Developmental cell 2014; 29(5): 621-8.

53. Harb R, Xie G, Lutzko $\mathrm{C}$, et al. Bone marrow progenitor cells repair rat hepatic sinusoidal endothelial cells after liver injury. Gastroenterology 2009; 137(2): 704-12.

54. Fantin A, Vieira JM, Gestri G, et al. Tissue macrophages act as cellular chaperones for vascular anastomosis downstream of VEGF-mediated endothelial tip cell induction. Blood 2010; 116(5): 829-40. 
55. DeFalco T, Bhattacharya I, Williams AV, et al. Yolk-sac-derived macrophages regulate fetal testis vascularization and morphogenesis. Proceedings of the National Academy of Sciences of the United States of America 2014; 111(23): E2384-93.

56. Ong K, Horsfall W, Conway EM, et al. Early embryonic expression of murine coagulation system components. Thrombosis and haemostasis 2000; 84(6): 102330 .

57. Si-Tayeb K, Lemaigre FP, Duncan SA. Organogenesis and development of the liver. Developmental cell 2010; 18(2): 175-89.

58. Nonaka H, Tanaka M, Suzuki K, et al. Development of murine hepatic sinusoidal endothelial cells characterized by the expression of hyaluronan receptors. Developmental dynamics : an official publication of the American Association of Anatomists 2007; 236(8): 2258-67.

59. Bautch VL, Caron KM. Blood and lymphatic vessel formation. Cold Spring Harbor perspectives in biology 2015; 7(3): a008268.

60. Gordon EJ, Gale NW, Harvey NL. Expression of the hyaluronan receptor LYVE-1 is not restricted to the lymphatic vasculature; LYVE-1 is also expressed on embryonic blood vessels. Developmental dynamics : an official publication of the American Association of Anatomists 2008; 237(7): 1901-9.

61. Orelio C, Dzierzak E. Identification of 2 novel genes developmentally regulated in the mouse aorta-gonad-mesonephros region. Blood 2003; 101(6): 2246-9.

62. Mascarenhas MI, Parker A, Dzierzak E, et al. Identification of novel regulators of hematopoietic stem cell development through refinement of stem cell localization and expression profiling. Blood 2009; 114(21): 4645-53.

63. Bale SS, Geerts S, Jindal R, et al. Isolation and co-culture of rat parenchymal and non-parenchymal liver cells to evaluate cellular interactions and response. Scientific reports 2016; 6: 25329.

64. Yao $\mathrm{H}$, Liu B, Wang X, et al. Identification of high proliferative potential precursors with hemangioblastic activity in the mouse aorta-gonad- mesonephros region. Stem cells 2007; 25(6): 1423-30.

65. Wu Y, Hu Z, Li Z, et al. In situ genetic correction of F8 intron 22 inversion in hemophilia A patient-specific iPSCs. Scientific reports 2016; 6: 18865. 


\section{FIGURE LEGENDS}

A)

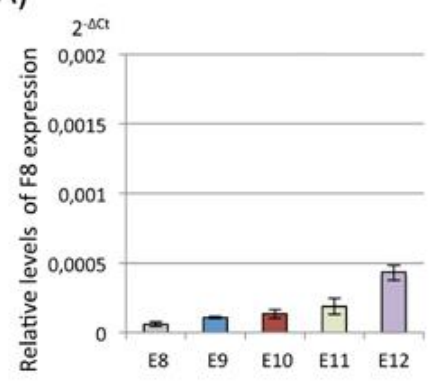

D)

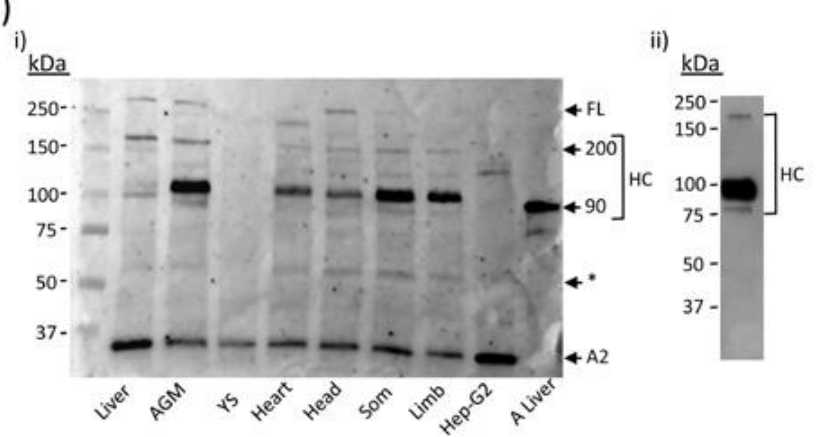

B)

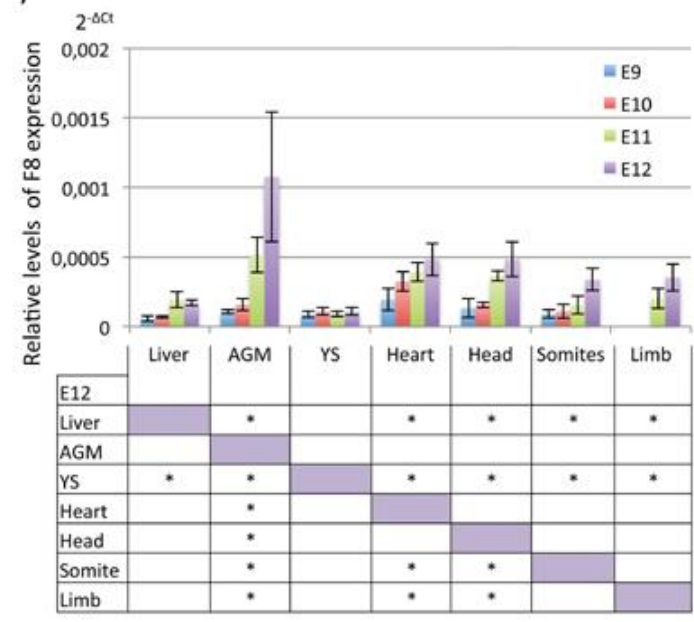

C)

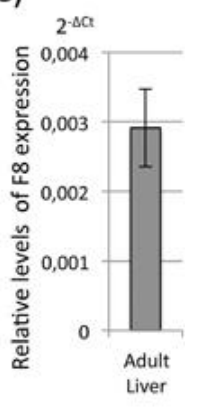

Figure 1. F8 expression during embryo development. (A) Quantitative PCR showing F8 relative expression in whole embryos at different stages. Histograms represent the mean $\pm S D$ values from biological replicated, samples, $n=3$. (B) Quantitative PCR showing F8 RNA relative expression levels obtained at different developmental stages for the indicated embryonic/fetal tissues. For E12 foetal liver and AGM region mean \pm SD values were obtained from 5 independent experiments. For the rest of the tissues $n=3$. (C) The relative levels of $F 8$ expression in adult liver used as positive control are shown, $\mathrm{n}=6$. GAPDH was used as normalization control. Statistical significance ( $\mathrm{P} \leq 0.05$ using a U-Mann-Whitney test) of the $F 8$ levels from E12 tissues is indicated with asterisks. (D) (i) FVIII production by Western blot. $20 \mu \mathrm{g}$ of total protein from E12 foetal tissues and HEPG2 cell line lysates and $5 \mu \mathrm{g}$ from adult tissue were run on a 7.5\% Tris acetate gel and blotted on NC membranes. (ii) 48 ug of total protein from adult liver was run. FVIII proteins were identified with a monoclonal antibody against FVIII A2 domain, an HRP-labelled secondary antibody and ECL detection reagent. FL, full length protein (A1-A2-B-A3-C1-C2 domains); SC, single heavy chain 
(A1-A2-B domains); HC, heavy chain (including different fragments from A1-A2-B domains); *, unspecific band.

A)

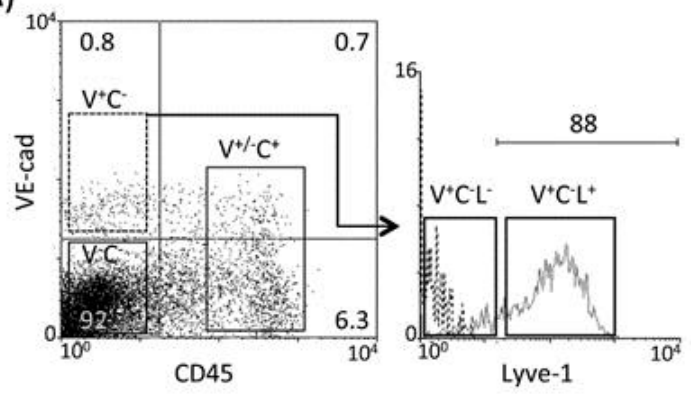

C)

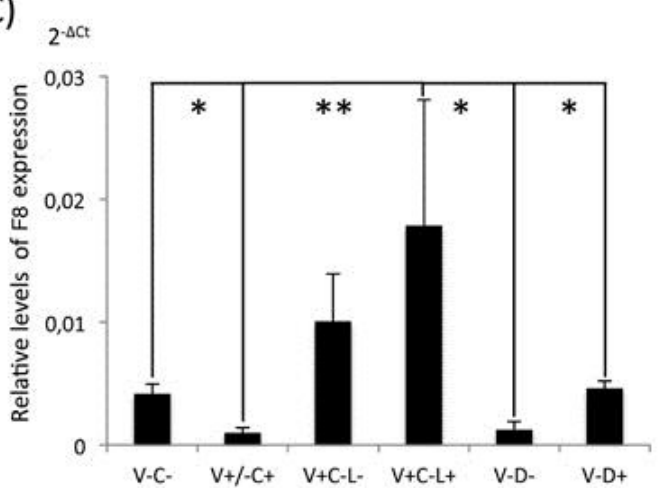

B)

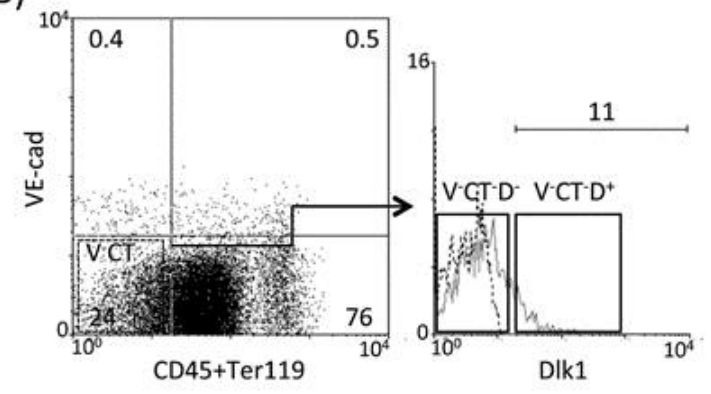

Figure 2. FVIII expression in E12 FL cell subsets. (A) FL cells were stained for 7AAD, VE-cad-APC (V), CD45-PE (C) and Lyve1-FITC (L). 7AAD- viable cells were gated and non-endothelial non-hematopoietic $\left(\mathrm{V}^{-} \mathrm{C}^{-}\right)$, hematopoietic $\left(\mathrm{V}^{+/-} \mathrm{C}^{+}\right)$, hemato-vascular progenitor $\left(\mathrm{V}^{+} \mathrm{C}^{-} \mathrm{L}^{-}\right)$and endothelial cell $\left(\mathrm{V}^{+} \mathrm{C}^{-} \mathrm{L}^{+}\right)$fractions isolated for RNA extraction. (B) FL cells were stained for 7AAD, VE-cad-APC (V), CD45-PE and Ter119-PE (CT) and DLK1-FITC (D). Gated non-hematopoietic/erythroid cells (V-CT-) (dotted gate) were subdivided according to Dlk1 expression into a mesenchymal enriched fraction (V-CTD-) and hepatoblast (V-CT- $\left.\mathrm{D}^{+}\right)$for RNA extraction. Percentage of cell population is indicated on each quadrant in the FACS dot plots. Percentage in the histogram plot is referred to the dotted line sorting gate. Representative values for one experiment are shown. $n=3$ sorting experiments using the $V-C$ - L staining strategy and $n=2$ for the V-CT-D staining strategy. (C) qPCR showing FVIII relative expression from sorted FL populations. The mean \pm SD values are represented. Values were obtained from $n=3 \mathrm{~V}$ C-L sorting experiments and $n=2 \mathrm{~V}-\mathrm{C}-\mathrm{T}-\mathrm{D}$ - sorting experiments, run simultaneously in triplicates for qPCR, Statistical significance using a U-Mann-Whitney test was indicated as $\mathrm{p} \leq 0.1\left(^{*}\right)$ and $\mathrm{p} \leq 0.01\left({ }^{* *}\right)$. 
A)

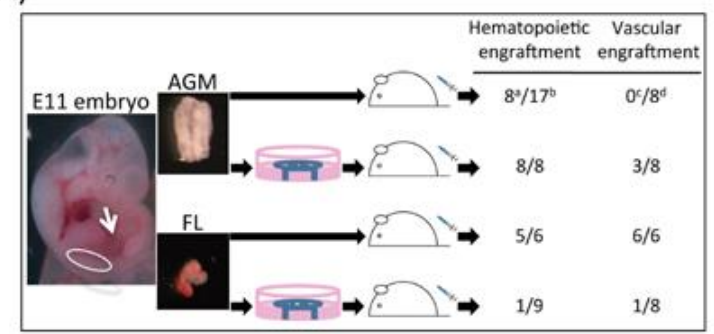

B)

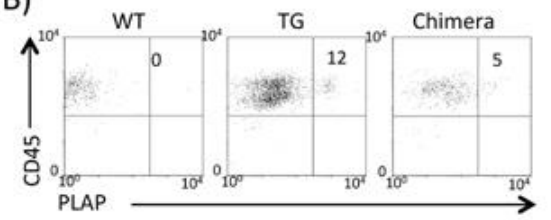

D)

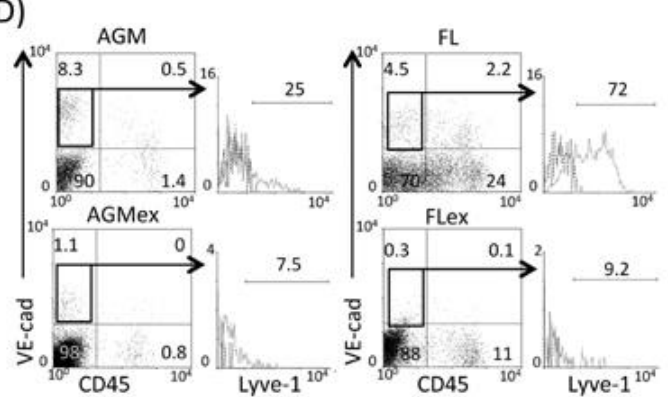

C)

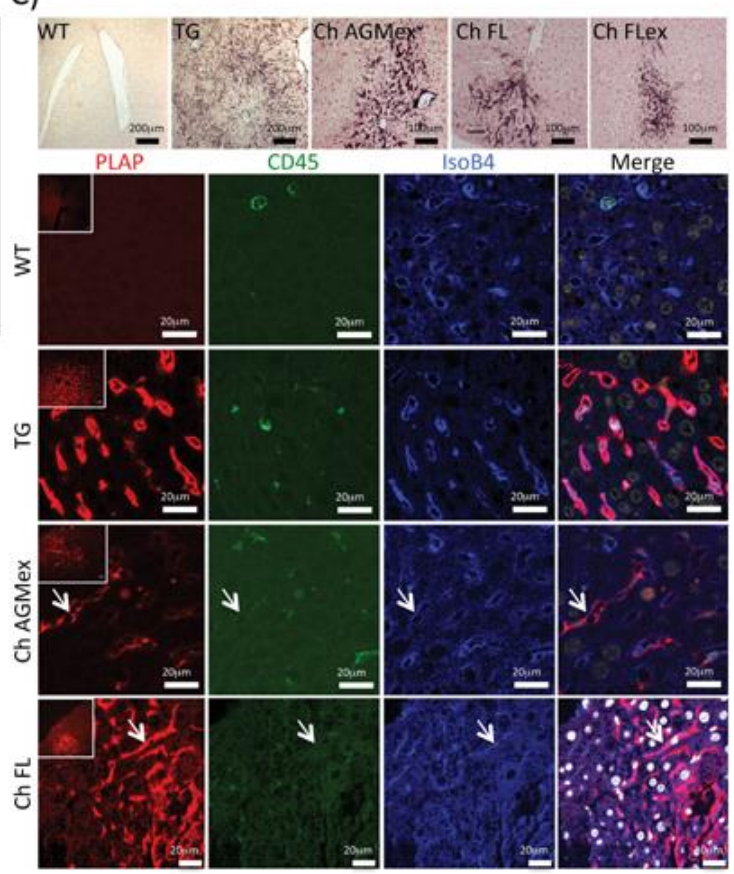

Figure 3. AGMex cultures expand cells with LSEC engraftment potential. (A) Experimental design. The AGM region (circle) and the liver (arrow) from E11 SCL-PLAP transgenic embryos were dissected. Tissues were homogenized for direct transplantation or explanted separately onto filters supported by stainless steel mesh stands at the air-liquid interface. Tissues were cultured for 3 days, dissociated and cells transplanted into busulfan conditioned new-born recipients to determine hematopoietic and LSEC engraftment activity at 4 months post-transplantation. The frequency of hematopoietic and vascular chimerism is indicated: a)number of recipient mice showing donor cells in peripheral blood; b)total number of mice transplanted; c)number blood chimeras showing donor derived LSECs clusters in the liver; d)total number of animals analysed for vascular chimerism. The number of transplantation experiments performed for each cell type were as follows, AGM, n=5; AGMex, $n=3$; FL, $n=4 ; F L e x, n=3$. (B) Analysis of AGMex cell hematopoietic engraftment in the peripheral blood. Representative flow cytometry analysis is shown comparing peripheral blood from representative WT, SCL-PLAP transgenic (TG) and AGMex chimera. Erythrocyte depleted peripheral blood cells were stained for the donor reporter marker PLAP and CD45. Mean \pm SD values for peripheral blood hematopoietic engraftment are shown in Table 2. The SCL-PLAP reporter gene is expressed in a fraction of mature circulating cells (FACS-PLAP, 15 $\pm 5 \%$ ). Value of $5 \%$ FACS-PLAP in the chimera is equivalent to 10 - 
100\% total hematopoietic chimerism as estimated by semi-quantitative PCR-PLAP (see Material and Methods.) (C) Top images represent liver section stained for the PLAP substrate NBT from the indicated representative mice. NBT positive vascular clusters are shown from AGMex, FL and FLex chimeras. Liver sections from 30 transplanted mice, including all blood chimeras were screened for detection of NBT positive vascular clusters and the relative vascular cluster area (v.c.a) indicated in Table 2. Immunofluorescence images from liver section from the indicated mice. PLAP+ clusters in liver sections chimeras are formed by elongated cells lining sinusoids expressing the endothelial marker Isolectine B4 (IsoB4) and very low/negative levels of the hematopoietic marker CD45, consistent with being LSECs (arrows). In the merge panels, DAPI nuclear staining is shown in grey. Inset images are set at lower magnification, presenting a PLAP+ cluster in the chimeras (Sup. Figure 1) (D) Phenotypic analysis of donor cells. FACS analysis was performed to compare the frequency of $\mathrm{V}^{+} \mathrm{C}-\mathrm{L}^{+/-}$cells before and after explant cultures of E11 FL and AGM cells. Representative dot plots and histograms are represented. Expansion of LSEC activity in AGMex does not correlate with an increment on $\mathrm{V}^{+} \mathrm{C}^{-} \mathrm{L}^{+/}$- frequency, $\mathrm{n}=2$. 


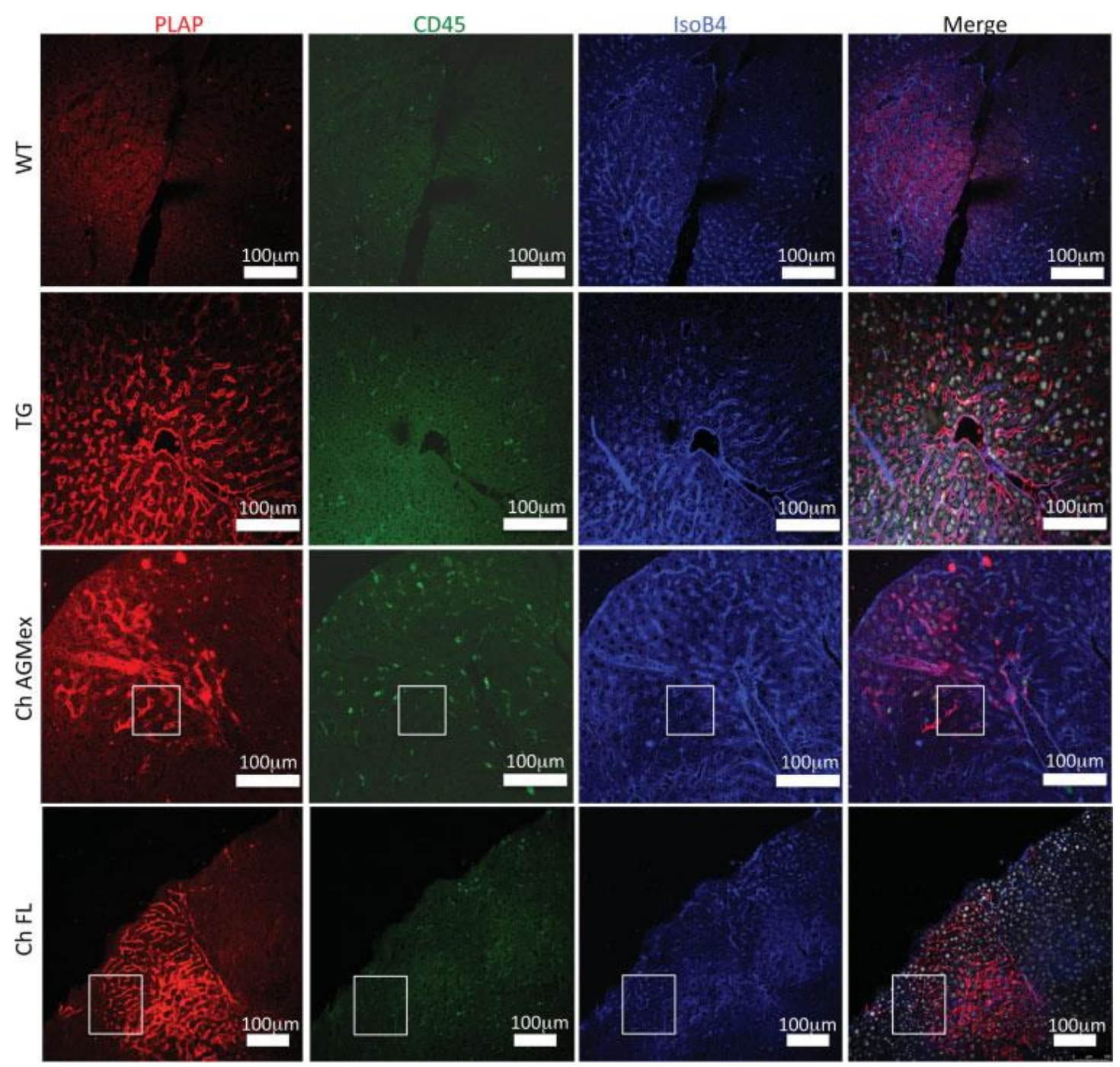

Sup. Figure 1. Immunofluorescence images from liver sections from AGMex and

FL chimeras. Low magnification images showing the extension of representative vascular clusters for the indicated chimeras. Sections were stained for detection of donor-derived marker PLAP, the hematopoietic marker CD45, the endothelial marker IsoB4 and DAPI for the nuclei. Magnified images of delimitated tissue area by white squares are shown in Figure 3C. 


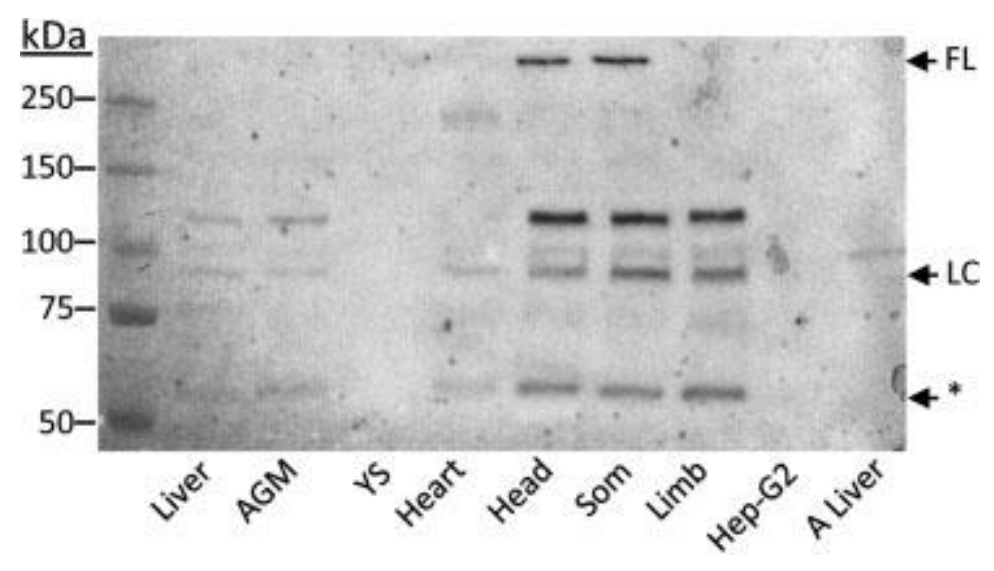

Sup. Figure 2. FVIII production by Western blot. $20 \mu \mathrm{g}$ of total protein from E12 foetal tissues and HEPG2 cell line lysates and $5 \mu \mathrm{g}$ from adult tissue were run on a 7.5\% Tris acetate gel and blotted on NC membranes. FVIII proteins were identified with a monoclonal antibody against FVIII LC domain, an HRP-labelled secondary antibody and ECL detection reagent. FL, full length protein (A1-A2-B-A3-C1-C2 domains); LC, light chain (A3-C1-C2 domains). *Unspecific band.

Table 1. Primers design for mouse F8 and GAPDH genes analysis

\begin{tabular}{llcc}
\hline \multirow{2}{*}{ Genes } & Sequences & $\begin{array}{c}\text { Amplified size } \\
\text { (bp) }\end{array}$ & Gene Bank \\
\hline \multirow{2}{*}{ Factor VIII } & 5'-GGTTTTTCAGGGGAATCAGGAC-3' $^{\text {5'-GCCTCAGAGCAATTTGGTGC-3' }}$ & 119 & NM_007977.1 \\
\hline \multirow{2}{*}{ GAPDH } & $\begin{array}{l}\text { 5'-CATGGCCTTCCGTGTTCCTA-3' } \\
\text { 5'-GCGGCACGTCAGATCCA-3' }\end{array}$ & 55 & NM_001289726 \\
\hline Abbreviations: bp, base pair; GAPDH, glyceraldehyde phosphate dehydrogenase. &
\end{tabular}


Table 2. AGM explant culture expands cells with LSECs engraftment activity

\begin{tabular}{|c|c|c|c|c|c|}
\hline \multicolumn{2}{|c|}{ Donor cells $^{\mathbf{a}}$} & \multicolumn{2}{|c|}{ Hematopoietic chimerism $^{b}$} & \multicolumn{2}{|c|}{ Vascular chimerismc $^{c}$} \\
\hline Tissue & $\begin{array}{c}\mathrm{n}^{\mathrm{o}} \text { cells } \times 10^{4} \\
\text { (ee) }\end{array}$ & $\begin{array}{l}\mathrm{n}^{\mathrm{o}} \mathrm{PLAP}^{+} / \\
\text {total mice }\end{array}$ & $\begin{array}{c}\% \mathrm{PLAP}^{+} \\
\text {(range values)g }\end{array}$ & $\begin{array}{l}\mathrm{n}^{\circ} \mathrm{PLAP}^{+} / \\
\text {total mice }\end{array}$ & $\begin{array}{c}\text { PLAP }^{+} \text {v.c.a. } \\
\text { x10-3 } \mathrm{cm}^{2} \\
\text { (range values) }\end{array}$ \\
\hline \multirow{2}{*}{ AGM } & $20-80$ & $8 / 17$ & $6.2 \pm 6$ & $0 / 8$ & 0 \\
\hline & $(1-4)$ & & $(1.5-15.7)$ & & \\
\hline \multirow{2}{*}{ AGMex } & 30 & $8 / 8^{e}$ & $11.6 \pm 9$ & $3 / 8$ & $0.9-0.13-0.04$ \\
\hline & $(2.5)$ & & $(9.5-13.4)$ & & \\
\hline \multirow{2}{*}{ FL } & $25-50$ & $5 / 6^{\mathrm{f}}$ & $10.6 \pm 6.7$ & $6 / 6$ & $1.2 \pm 0.5$ \\
\hline & $(2-4)$ & & $(5-18)$ & & $(0.27-1.63)$ \\
\hline \multirow{2}{*}{ FLex } & $8-100$ & $1 / 9$ & 11.4 & $1 / 8$ & 0.14 \\
\hline & $(2-4)$ & & & & \\
\hline
\end{tabular}

Abbreviations: AGM, aorta-gonads-mesonephros; AGMex, aorta-gonads-mesonephros explant; $F L$, foetal liver; Flex, foetal liver explant; LSEC, liver sinusoidal endothelial cell; NBT, nitroblue tetrazolium; PCR, polymerase chain reaction; $S D$, standard deviation.

Note: Data were obtained from mice generated from the following number of independent transplantation experiments: $A G M, n=5 ; A G M e x, n=3 ; F L, n=4 ; F L e x, n=3$; ee, embryo equivalent.

aBusulfan conditioned new-born mice were i.v. transferred with the indicated number of cells from uncultured or 3 days explanted tissue obtained from E11 SCL-PLAP transgenic embryos. Transplanted mice were analysed at 4 months post-transplant for hematopoietic and vascular engraftment.

bHaematopoietic chimerism was expressed as the frequency of $\mathrm{PLAP}^{+}$leukocytes in the host circulation assessed by flow cytometry.

cVascular chimerism was determined by histological NBT detection of $\mathrm{PLAP}^{+}$donor-derived cells forming vascular-like clusters on liver sections and animals scored as positive when at least one vascular cluster was observed. The mean values of relative tissue area containing the PLAP+ vascular-like clusters referred to the total tissue area analysed are indicated for each group (vascular cluster area, v.c.a.).

d Chimerism determined in peripheral blood by flow cytometry. The number of PLAP+ chimeras related to the total analysed mice is shown.

e One AGMex chimera was only analysed by PCR-PLAP

${ }^{f}$ Two FL chimeras were only analysed by PCR-PLAP.

9 Mean \pm SD values for $\%$ PLAP+ cells in the circulation from positive mice. $\%$ PLAP from SCL3 'Enh-PLAP transgenic animals were $15 \pm 5 \%$.

h Positive animals presenting PLAP+ vascular clusters in liver sections stained for NBT from the total number of analysed mice. Analysed mice include all PLAP+ haematopoietic chimeras and 1 FL and 7 FLex transplanted mice not presenting haematopoietic chimerism. 
Sup. Table 1. Regression analysis of F8 RNA level increment with age.

\begin{tabular}{lllllllll}
\hline LOG & WE & Liver & AGM & YS & Heart & Head & Limb & Somite \\
\hline Intercept & -13.22 & -13.30 & -16.70 & -9.73 & -11.35 & -14.30 & -14.85 & -13.34 \\
Slope & 0.44 & 0.40 & 0.82 & 0.045 & 0.31 & 0.57 & 0.57 & 0.42 \\
$\mathrm{R}^{2}$ & 76.16 & 53.52 & 88.48 & 4.19 & 57.38 & 74.11 & 49.15 & 58.94 \\
P-Value & $<10^{-4}$ & $<10^{-4}$ & $<10^{-4}$ & 0.231 & $<10^{-4}$ & $<10^{-4}$ & 0.0012 & $<10^{-4}$ \\
\hline
\end{tabular}

Abbreviations: AGM, aorta-gonads-mesonephros; RNA, ribonucleic acid; WE, whole embryo; YS, yolk sac.

Note: To determine the statistical significance of F8 RNA levels increment with age, a regression analysis was performed for whole embryos (WE) and indicated tissues obtained from stages E8 to E12 as shown in Figure 1. The logarithm 2- $\Delta \mathrm{Ct}$ values for F8 RNA were used as dependent variable. Results of the analysis indicate that there is a significant $(\mathrm{p}<0.05)$ correlation of age and F8 RNA production in most samples, except for the yolk sac (YS), where the low levels for F8 RNA do not increment with the developmental stage. 
EXTRA TABLE

What is known about this topic?

- Coagulation factor VIII (FVIII) is produced by endothelial and some hematopoietic cells in adult individuals.

- Transplantation of adult liver sinusoidal endothelial cells (LSECs) and bone marrow-derived hematopoietic cells into adult FVIII deficient haemophilic A mice ameliorates the coagulation defect, constituting targets for HA cell therapeutic approaches.

- Foetal hematopoietic and endothelial progenitor cells present an improved hemato and vascular engraftment potential compared to adult counterpart cell types, particularly in neonatal host receptors, however less is known about foetal liver (FL) and AGM FVIII production and LSEC activity generation in vitro.

What does this paper add?

- FVIII transcripts are produced in the foetal liver and AGM region, main hematopoietic locations during mid-gestation developmental stage.

- FVIII transcripts are mainly produced by a FL derived cell population with LSEC engraftment potential in new-born receptors.

- AGM explanted cultures increment hematopoietic and LSEC engraftment activity.

- Highlights the potential foetal derived cells have for HA cell therapeutic approaches in young individual. 